\title{
A novel performance evaluation technique based on integrated weighting approach: A case study in the field of sport management
}

\author{
Ömer Faruk Görçün ${ }^{a^{*}}$ and Hande Küçükönder ${ }^{b}$
}

a Department of International Logistics \& Trade at Kadir Has University, Kadir Has University, Cibali Av. Kadir Has St. Fatih / ISTANBUL 34083, Turkey

${ }^{b}$ Department of Numerical Methods, Faculty of Economics and Administrative Sciences, Bartın University, Bartın, Turkey

\begin{tabular}{l}
\hline C H R O N I C L E \\
\hline Article history: \\
Received November 11, 2020 \\
Received in revised format: \\
May 23, 2021 \\
Accepted May 232021 \\
Available online \\
May 27, 2021 \\
\hline Keywords: \\
Player Selection \\
WASPAS \\
CRITIC \\
PSI \\
Weight aggregation operator
\end{tabular}
\begin{abstract}
A B S T R A C T
It is a fact accepted by everybody that football is the most popular sport around the world. The result of a derby match may be very important for millions of people. Even the time seems to stop on a match day for so many people. Show and entertainment are the most important aspects of football. If soccer players have a high performance, a match may provide pleasure and excitement to audiences. Briefly, the performance and quality of soccer players are the key factors, which draw audiences. Goalkeepers are also one of the important components of football like other players playing different positions such as strikers, mid-fielders, and defenders. Moreover, a goalkeeper can affect the result of a match positively or negatively. Therefore, with the help of a mathematical approach as the methodological framework, it can be seen that the examination of the performance of goalkeepers can be beneficial for decision-makers performing in the fields of sport and the future studies. The current paper proposes an improved integrated multi-criteria decision-making approach to evaluate the selection of goalkeepers; and this model can be applied for goalkeeper's performance analysis. The proposed model combines the weights of criteria calculated with the help of both the CRITIC and the PSI techniques by applying the weight aggregation operator. It also ranks the decision alternatives by implementing the WASPAS technique based on the final criteria weights obtained by using the weight aggregation operator. In addition, a comprehensive sensitivity analysis consisting of three stages was performed to verify the validation of the suggested hybrid model. It has been observed that A11 has remained the best option for all scenarios. As a result, the results of the sensitivity analysis prove that the proposed hybrid MCDM technique is a very useful, strong and applicable approach. Also, the results obtained by applying the proposed model are accurate, realistic, and reasonable according to the results of the validation test.
\end{abstract}

\section{Introduction}

In recent years, football has become an industry; and the numbers of factors and variables affecting success have increased considerably. Football has become a more complicated branch of sport in the last decades. Nowadays, the proper soccer player selection is also a decision-making problem, which is both complicated and time-consuming for decision-makers because there are many factors and variables that can affect the selection process. Therefore, the selection of the proper player is a crucial subject for football clubs to succeed. This paper proposes a novel integrated multi-criteria decisionmaking model for solving the decision-making problems about soccer player selection. In order to obtain more rational and applicable results, a board of experts that consists of seven members was constructed; and many roundtable meetings were organized to determine the selection criteria and decision options. All of the members are veteran soccer players. More importantly, they closely follow the Turkish and international football leagues in addition to the English Premier League. In the roundtable meetings, twenty selection criteria for evaluating the goalkeepers' performances and twenty-four

* Corresponding author.

E-mail address: omer.gorcun@khas.edu.tr (Ö. F. Görçün)

(C) 2021 by the authors; licensee Growing Science, Canada. doi: $10.5267 /$ j.dsl.2021.5.004 
goalkeepers were determined as decision alternatives. In determining the decision alternatives, factors directly affecting the performances have been defined by the board of experts considering the evaluation of the international football associations about players' efficiencies. As decision alternatives, goalkeepers who played at least 500 minutes in the season of 20192020 of the English Premier League were selected. All statistical data about soccer players were collected from official statistics published by the English Premier League. In this paper, the proposed integrated approach is a novel and modified multi-criteria decision-making model. Initially, it is required to point that traditional CRITIC and the PSI techniques do not work if there are any negative or zero scores in values of indexes. Therefore, this method has been modified by using the $\mathrm{Z}$-score technique. In order to calculate the weights of the criteria, two weighting techniques were applied separately. Then, the results of both techniques were combined by implementing the weight aggregation operator. Afterward, the WASPAS method was implemented for calculating the relative importance values of decision alternatives. Considering these values, decision options were ranked. The CRITIC and the PSI methods are novel MCDM techniques used for calculating the weights of factors. Even though these methods are new approaches, they are very important tools implemented to solve complicated decision-making problems in various fields. Also, the WASPAS method is a novel MCDM method; and it has noteworthy abilities to determine the best and proper alternatives in the selection problems. The proposed integrated approach can contribute to literature about the soccer player selection and players' performance analysis as follows:

- This paper proposed a methodological framework to evaluate soccer players' performance and the proposed mathematical model takes into consideration many factors and variables to make an applicable and realistic performance analysis.

- Besides providing very effective and applicable results for solving the goalkeepers' selection problem, it can be implemented to evaluate the performance of these players. Moreover, it can be applied for different decision-making problems faced in many fields.

- For football clubs, it may be a very beneficial and effective tool for evaluating goalkeepers the clubs plan to transfer. The proposed integrated MCDM approach can be implemented in the decision-making problems in the field of sport management and sport science; and it can also be applied for making player performance analysis in other branches of sports.

In the current study, a novel integrated multi-criteria decision-making model is proposed to solve the decision-making problem about goalkeeper selection. In addition to that, the critic method, which is a part of the suggested model has been improved; and the negative value transformation technique has been integrated into this method. In the second phase of the model, the goalkeeper selection problem has been solved using the WASPAS method; and all decision alternatives have been ranked considering the relative importance scores.

This paper is organized in six sections. In the first section, the main problem and solution are summarized. In the second section, a literature review is given; and previous studies are reviewed from a broad point of view. The proposed multicriteria decision-making model has been introduced; and its implementation algorithm has been presented in the third section. In the fourth section, a numerical analysis is carried out. In the fifth section, the obtained results and findings are evaluated and discussed. In the sixth and final section of this paper, the obtained results and findings of this study are evaluated and discussed, some suggestions are also made for the future studies in the final section of this paper.

\section{Literature Review}

When the literature is reviewed, it can be seen that it is limited and scattered. Although some studies about player selection are available, any study focusing directly on the goalkeeper selection is not available in the literature. In addition to that, there are a limited number of studies related to player selection that use the MCDM methods. In recent years, methodological approaches have been applied to evaluate the players, teams, and club performances; and these techniques have also been implemented to solve decision-making problems faced in the fields of sports. Obtained results are promising, but they are not sufficient. Depending on the increasing number of these kinds of studies, the sport industry can obtain more benefits from the outputs and results of these studies. In fact, there are many factors and variables affecting the selection process and results. Therefore, evaluation of the player and team performance or selection of the proper player is a decision-making problem. These kinds of problems can only be solved by using the proper multi-criteria decision-making techniques. Using MCDM techniques provides a methodological framework to decision-makers; and it is a requirement to solve decisionmaking problems faced in the fields of sports. As mentioned above, there are a limited number of studies about performance analysis or evaluation of selections. Nonetheless, when the literature is reviewed, it can be seen that there are some successful samples available. While some of them are related to performance analysis, others are concerned with selection problems in the field of sports. Some authors focused on the performance evaluation of players or teams. An experimental study was carried out by Casals and Martinez (2013) for evaluating the basketball players' performances; and they identify the main variables and factors affecting the player performance. Balli and Korukoğlu (2014) proposed a hybrid MCDM model that consists of the fuzzy analytic hierarchy process and the technique for order preference by similarity to ideal solution (TOPSIS) to solve the decision-making problems about basketball player selection. Jarvandi, Sarkani, and Mazzuchi (2013) examined the skills and potential role of each player and developed a model to evaluate the performance of each player. Vaeyens et al. (2006) tried to identify the relationships existing among all factors affecting the players' efficiencies. Djordjevic, Vujosevic, and Martic (2015) examined the technical performance of the teams racing in the world 
cup with the help of data envelopment analysis (DEA) technique. Kedar-Levy and Bar-Eli (2008) developed a model to calculate the players' values in the future by using conventional regression models. Duch, Waitzman, and Amaral (2010) tried to determine the quantitative values for players' personal characteristics.

Evaluation of the player selection, which is the main focal point of this paper, is crucial for team performance and success. The number of studies focusing on the player selection problem has started to increase during recent years. Within this context, Karsak (2000) suggested a multi objective fuzzy programming model for identifying the quantitative values for all variables and factors. Korvin, F. Shipley, and Kleyle (2002) introduced a model proposing the most suitable players under situations of budget constraint. Hu, Zhou, Zhang, and Zhao (2015) suggested a DEA model as a methodological framework for determining the proper sports coaches. Mirabile and Witte (2015) developed a model for choosing suitable players for university teams. Qader, BB, Ali, Kamaluddin, and Radzi (2017) implemented the TOPSIS method to solve the player selection problems. Some studies examined the factors affecting the players' performance; and they asserted that some match statistics such as passing, shots, goal, and foul can be evaluated as main indicators of team and player performance (Woods, Raynor, Bruce, McDonald, and Robertson, 2016). According to the main findings of a study carried out by Fernandez-Navarro, Fradua, Zubillaga, Ford, and McRobert (2016), the long pass abilities of players influence the teams' direct play strategy and effectiveness. In addition to those, the majority of these studies tried to detect whether there is a positive correlation between teams' success and players' abilities; and almost all of them argued that if a team usually touches the ball more than its competitors, it stands a good chance of winning the match (Tenga, Holme, Ronglan, and Bahr, 2010). In this respect, ball possession has also been reported by Lago-Ballesteros and Lago-Penas (2010) as a variable decisively affecting the performance of football teams.

Even though there are many studies using multi-criteria decision-making techniques in various fields, studies in the field of sports science and management by using the MCDM methods are extremely few. In addition to that, applied methods are not novel in these studies. Moreover, there is no study making a performance analysis or evaluating the player selection using an integrated MCDM approach in the field of sports.

This paper has the potential to contribute to the literature within this framework; and it aims to fill these gaps in the literature. Therefore, the main aim of this paper is to suggest an applicable integrated multi-criteria decision-making approach as a methodological framework to solve decision-making problems faced in the fields of sports. This proposed model can be applied to various decision-making problems such as both performance analysis and player selection. In addition to those, it is a novel MCDM approach; and it has not been applied before in any study.

\section{The proposed MCMD framework}

Here, the proposed integrated MCDM approach and its basic algorithm are presented. The implementation steps and general structure of the proposed model are given in Fig. 1. In the first phase of the proposed model, a set of research questions was determined to define the main problem as follows:

- Is there any mathematical model applied to solve decision-making problems on player selection in the field of sport industry?

- Do decision-makers decide to select the proper player based on their own experinces and individual judgements only?

- What are the significant selection criteria for determining the appropriate players?

- Is it possible to implement a mathematical model for evaluating the alternatives in the field of sport industry?

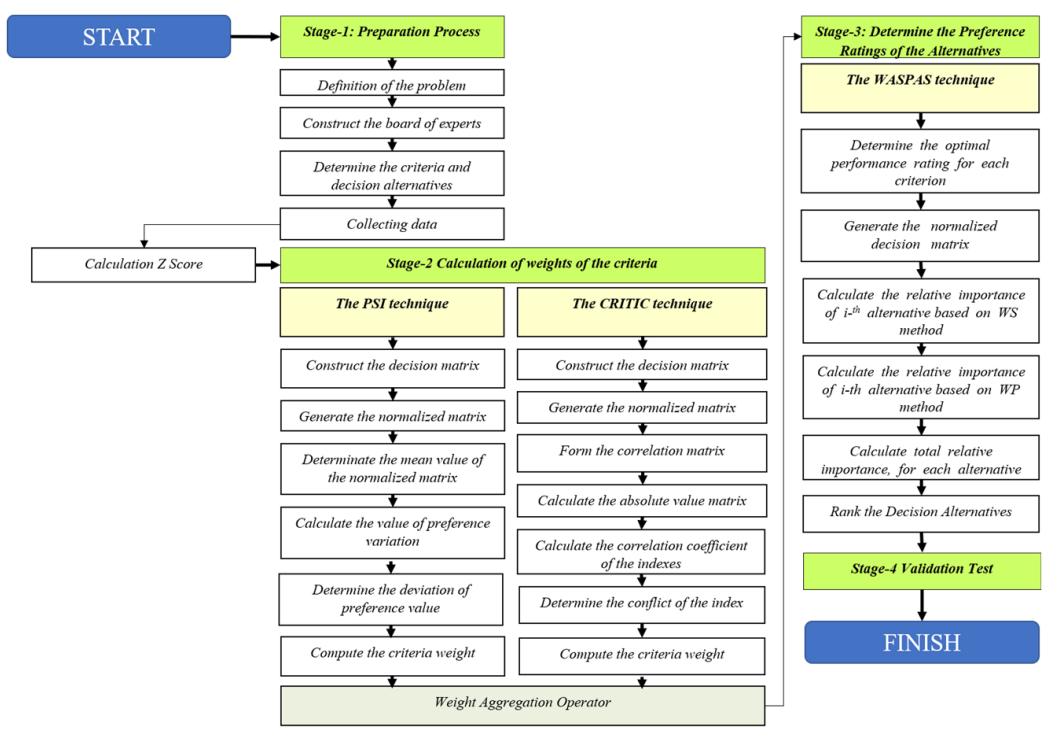


Fig. 1. The basic algorithm of the proposed MCDM approach

Next, these questions were directed to the experts who are members of the board of experts by organising a face-to-face interview with the expert in addition to many well-attended round-table meetings. At the end of the process, preparing a list to determine the selection criteria was requested from each expert by researchers. After the lists were collected, researchers eliminated the repetitive criteria and presented the final list for criteria. Finally, the selection criteria were determined by providing full consensus among the members of the board. Then, the crisp data was collected; and the proposed hybrid technique was implemented.

3.1. Implementation of the Z-Score Technique: During the calculation of the weights of the factors, it is not possible to compare different dimensions existing among different indexes. In this respect, some weighting methods such as entropy, critic, etc. cannot be applied even if the value of a matrix element takes negative or zero scores. All matrix elements' values should be positive. If they are not, the negative value transformation operation can be applied for these negative values to convert to positive values. This technique consists of two implementation steps (Q. Zhang, Xu, \& Zhang 2014). In the first step, the standard scores (Z-score) are computed; and a new matrix is constructed.

In the second step of the method, absolute value of the minimum value of the standard score matrix is calculated; and the score of $\mathrm{A}$ is computed adding 0.1 value. The decision matrix is constructed by adding the score of $\mathrm{A}$ to all matrix elements separately.

$x_{i j}=\frac{\left(x_{i j}-\bar{x}_{i}\right)}{s_{i}}$

In the second step of the method, absolute value of the minimum value of the standard score matrix is calculated; and the score of $\mathrm{A}$ is computed adding 0.1 value. The decision matrix is constructed by adding the score of $\mathrm{A}$ to all matrix elements separately.

$x_{i j}^{\prime}=\left(x_{i j}+A\right)$

3.2. Calculation of the Weights of the Criteria: Here, we applied both the CRITIC technique and the PSI method to calculate the criteria weights. Next, the calculated weights of criteria by applying both techniques were combined with the help of weighting aggregating operator. Implementation of these techniques and their implementation steps are given below:

a) The CRITIC Technique: The CRITIC (criteria importance through inter-criteria correlation) technique, introduced by Diakoulaki, Mavrotas, and Papayannakis (1995), is a very useful computational tool applied successfully in various fields. In brief, this method focuses on the differences and correlation among the selection criteria. If the conflict between the two indexes is high, the positive correlation is also weak. Therefore, the weight value for a factor can be accepted as low. The CRITIC method has a very simple algorithm consisting of three implementation steps as follows: (Deng, Yeh, \& Willis 2000; Wang \& Luo 2010).

Step-1: Construct Decision Matrix: In this step, a decision matrix is constructed and $x_{i j}^{\prime}$ represents performance of $i^{\text {th }}$ alternative for $j^{\text {th }}$ criterion.

$$
X=\left[x_{i j}^{\prime}\right]_{m x n}
$$

Step-2: Normalization of Decision Matrix X: The decision matrix is normalized with the help of equations 4 and 5 . While eq 4 is used for benefit criteria, eq 5 is applied for cost criteria.

$$
\begin{aligned}
& x_{i j}^{*}=\frac{x_{i j}^{\prime}}{\max x_{i j}^{\prime}} \\
& x_{i j}^{*}=\frac{\min x_{i j}^{\prime}}{x_{i j}^{\prime}}
\end{aligned}
$$

Step-3: Calculation of the Weight Values of Criteria: The weights of criteria are computed by using equations 6,7 , and 8. At first, the correlation coefficient of the indexes is computed as follows:

$$
r_{i j}=\frac{\sum_{i=1}^{n}\left(d_{i, k}-\left(\frac{1}{n}\right) \sum_{i=1}^{n} d_{i, k}\right)\left(d_{i, j}-\left(\frac{1}{n}\right) \sum_{i=1}^{n} d_{i, j}\right)}{\sqrt{\sum_{i=1}^{n}\left(d_{i, k}-\left(\frac{1}{n}\right) \sum_{i=1}^{n} d_{i, k}\right)^{2} \sum_{i=1}^{n}\left(d_{i, j}-\left(\frac{1}{n}\right) \sum_{i=1}^{n} d_{i, j}\right)^{2}}}
$$


The conflict of the index $C_{i}$ with other indexes can be expressed as follows:

$C_{i}=\sigma \sum_{j=1}^{n}\left(1-r_{i j}\right)$

The weight value of each criterion is calculated with the help of eq 8 .

$w_{j}=\frac{C_{i}}{\sum_{j=1}^{n} C_{i}}$

where $C_{i}$ denotes the amount of information of $j^{\text {th }}$ criterion, $\sigma$ is standard deviation, $r_{i j}$ is the correlation coefficient between $i^{\text {th }}$ and $j^{\text {th }}$ criterion, and $w_{j}$ symbolizes the weight of the $j^{\text {th }}$ criterion.

b) The Preference Selection Index Technique (the PSI): The PSI technique is a MCDM method applied to calculate the weights of criteria. It was developed by Maniya and Bhatt (2010), and is a very strong and applicable approach. The most important advantage of the technique is to have a basic algorithm that is applicable and easy to follow. The basic algorithm of the technique is given as follows: (Maniya \& Bhatt 2010; Jian \& Ying 2017; Sahir, 2018).

Step-1: Form the initial decision matrix: In this step, a decision matrix is constructed and $d_{i j}$ represents performance of $i^{\text {th }}$ alternative for $j^{\text {th }}$ criterion. Suppose $A=\left\{A_{1}, A_{2}, \ldots, A_{n}\right\}$ is the set of alternatives and $C=\left\{C_{1}, C_{2}, \ldots, C_{n}\right\}$ is the set of the criteria

$X=\left[x_{i j}^{\prime}\right]_{m x n}$

Step-2: Normalize the decision matrix: By applying equation 10, the elements of the initial decision matrix are standardized as follows.

$r_{i j}^{*}=\left\{\begin{array}{l}\frac{x_{i j}^{\prime}}{\max x_{i j}^{\prime}} ; j \in B \\ \frac{\min x_{i j}^{\prime}}{x_{i j}^{\prime}} ; j \in C\end{array}\right.$

Where $B$ is the set of benefit criteria and $C$ is the set of cost criteria.

Step-3: Determination of the mean value of the normalized matrix: The mean value of the normalized matrix is computed with the help of equation 11.

$N=\frac{1}{N} \sum_{i=1}^{m} r_{i j}^{*}$

Step-4: Calculate the value of preference variation: The preference variation value calculated by using equation 12.

$\phi_{j}=\sum_{i=1}^{m}\left|r_{i j}^{*}-N\right|^{2}$

Step-4: Determine the deviation of preference value: The deviation of preference value calculated by using equation 13.

$\Omega_{j}=1-\phi_{j}$

Step-5: Compute the weight value of each criterion: Weights of criteria are calculated by applying equation 14.

$w_{j}=\frac{\Omega_{j}}{\sum_{i=1}^{n} \Omega_{j}}$

c) Weight aggregation operator: The weights of criteria may be quite important and determinative, and can widely affect the evaluation results in an assessment process performed for solving a decision-making problem. Some weighting techniques such as AHP, ANP, DEMATEL, LBWA, BWM, FUCOM, Entropy, and CRITIC are MCDM methods that have been commonly used in previous studies. However, criteria weights can dramatically be affected by structuraldata attributes and subjective evaluations and judgments of decision-makers (Yazdani et al., 2020; Torkayesh et al., 2021). It can affect 
the evaluation of the decision alternatives and obtaining irrational and nonrealistic results is quite likely at the end of an evaluation process (Ecer, 2020).

In the current paper, two weighting techniques such as the CRITIC and the PSI methods were applied to determine the weight values of the criteria. Then, the final weight of each criterion was computed by using the weight aggregation operator. In literature, it has been observed that the operator was used by some authors for re-calculating weights of criteria determined by using subjective weighting techniques.

For instance, while Yazdani et al. (2020) used this approach for combining the weighting values of criteria obtained by applying the DEMATEL and BWM, Torkayesh et al. (2021) applied this operator to determine the final weights of criteria calculated with the help of both the BWM and LWBA techniques.

In this study, this operator is used to combine the weights of criteria calculated by applying both the CRITIC and the PSI methods. With the help of this technique, the final weight value of each criterion is computed. In this respect, $\mathrm{Sj}$ and $\mathrm{Kj}$ values denote the weights of criteria determined by using both techniques respectively; and the final weight of the jth criterion is calculated by using equation 15. (Torkayesh et al., 2021; Yazdani et al., 2020):

$w_{j}=\frac{s_{j} k_{j}}{\sum_{j=1}^{m} s_{j} k_{j}}$

d) The WASPAS Technique: Although the WASPAS (Weighted Aggregated Sum Product Assessment) method introduced by Chakraborty and Zavadskas (2014) is a very novel MCDM method, it can be seen that this technique has given very successful and realistic results in various fields. In fact, by combining the two MCDM methods such as weighted sum model (WSM) and weighted product model (WPM), the WASPAS (Vinchurkar and Samtani 2019) method was constituted. The WASPAS method has a very simple algorithm consisting of the five implementation steps; and these steps can be seen below: (Mardani et al. 2017; Karabasevic et al. 2016; Deveci et al. 2018; Vujić et al. 2016).

Step-1: Construct Decision Matrix X: In the first step of the WASPAS method, the decision matrix X, which consists of m number of alternatives and n number of criteria, is constructed. $x_{i j}^{\prime}$ represents the performance of ith option with respect to $j^{\text {th }}$ factor.

Step-2: Normalization of Performance Values: The decision matrix is normalized with the help of equation 16.

$x_{i j}^{-}=\left\{\begin{array}{l}\frac{x_{i j}^{\prime}}{\max x_{i j}^{\prime}} ; j \in B \\ \frac{\min x_{i j}^{\prime}}{x_{i j}^{\prime}} ; j \in C\end{array}\right.$

$i=(1,2, \ldots m)$ and $j=(1,2, \ldots, n)$

Where $B$ is the set of benefit criteria and $C$ is the set of cost criteria.

Step-3: Compute the measures of WSM ${ }_{i}{ }^{l}$ for each alternative as follows:

$p_{i}^{1}=\sum_{j=1}^{n} \overline{x_{i j}} w_{i}$

Step-4: Compute the measures of WSP $p_{i}^{2}$ for each alternative as follows:

$p_{i}^{2}=\prod_{j=1}^{n}\left(x_{i j}^{-}\right)^{w_{i}}$

Step 5. Calculate the aggregated measure of the WASPAS method for each alternative using the following expression: (Deveci et al., 2018)

$p_{i}=\alpha p_{i}^{1}+(1-\alpha) p_{i}^{2}$

Step 6. Rank the alternatives considering the decreasing values of $P_{i}$

\section{A Numerical Illustration}

Here, we applied the proposed integrated multi-criteria decision-making approach to evaluate the performance of goalkeepers competing in the English Premier League in order to demonstrate the implementation of the suggested model. In the first stage of the proposed model, the main problems have been determined. Next, a board of experts was constructed by researchers in order to obtain more rational, accurate, and reasonable results. Details of the members of the board of experts are given in the following table. 
Table 1

Details of the Members of the Board of Experts.

\begin{tabular}{lllr}
\hline No & Graduation Degree & Duty & Experience \\
\hline DM-1 & Sport Academy & Football coach & 13 \\
DM-2 & Sport Academy & Football coach & 13 \\
DM-3 & English Business Adm. and Man. & Branch Manager & 12 \\
DM-4 & Business Management & Vice-Branch Manager & 24 \\
DM-5 & Sport Academy & Sport Journalist & 10 \\
DM-6 & Sport Academy & Fotball commendator & 21 \\
DM-7 & Sport Academy & Former Fotball Player & 17 \\
\hline
\end{tabular}

The research questions were directed to the members of the board. According to the opinions of the experts, there is no commonly held mathematical model implemented to solve decision-making problems encountered in the field of sport management. Mostly, decision-makers (i.e. club chairmen, football coaches, managers of football branch of clubs) make decisions based on their experiences, knowledge, and individual judgments. Then, the lists prepared by experts were collected; and researcher eliminated the repetitive criteria to determine the final selection criteria. Afterwards, the relative importance score between 1 and 9, each determined by each expert, and the final significance scores of each criterion were defined by calculating the geometric means of given scores.

Table 2

The selection criteria for goalkeeper selection and relative importance scores.

\begin{tabular}{|c|c|c|c|c|c|c|c|c|c|}
\hline Code & Criteria & DM1 & DM2 & DM3 & DM4 & DM5 & DM6 & DM7 & Mean \\
\hline$C 1$ & Total Tackles & 4 & 7 & 8 & 8 & 6 & 9 & 7 & 7.3739 \\
\hline$C 2$ & Dribbled Past & 6 & 8 & 9 & 7 & 7 & 5 & 6 & 7.0278 \\
\hline C3 & Interception & 10 & 6 & 8 & 8 & 7 & 5 & 5 & 6.3210 \\
\hline C4 & Fouled & 1 & 9 & 9 & 7 & 8 & 9 & 9 & 8.5377 \\
\hline C5 & Fouls & 12 & 8 & 7 & 7 & 6 & 5 & 5 & 6.2016 \\
\hline C6 & Yellow Card & 13 & 7 & 5 & 7 & 7 & 6 & 6 & 6.0844 \\
\hline$C 7$ & Red Card & 2 & 9 & 8 & 8 & 9 & 7 & 9 & 8.3953 \\
\hline$C 8$ & Clearance & 15 & 5 & 8 & 7 & 6 & 5 & 5 & 5.9106 \\
\hline$C 9$ & Goal Saved & 17 & 7 & 5 & 8 & 5 & 5 & 6 & 5.7586 \\
\hline C10 & Unsuccessful Touches & 9 & 7 & 6 & 6 & 7 & 7 & 5 & 6.5070 \\
\hline$C 11$ & Aerial Won & 16 & 6 & 7 & 5 & 6 & 6 & 4 & 5.7652 \\
\hline C12 & Aerial Lost & 14 & 6 & 7 & 6 & 6 & 7 & 5 & 5.9519 \\
\hline$C 13$ & Accurance Long Pass & 7 & 7 & 6 & 7 & 7 & 8 & 8 & 6.9589 \\
\hline C14 & Accurance Short Pass & 11 & 7 & 5 & 6 & 7 & 7 & 6 & 6.3840 \\
\hline$C 15$ & Goal Concede & 8 & 6 & 7 & 7 & 6 & 8 & 6 & 6.6787 \\
\hline C16 & Clean Sheets & 3 & 8 & 6 & 8 & 8 & 9 & 7 & 7.6606 \\
\hline \multirow[t]{6}{*}{$C 17$} & Point Per Match & 5 & 8 & 6 & 6 & 9 & 7 & 7 & 7.2133 \\
\hline & Injuries & 5 & 3 & 3 & 5 & 4 & 4 & 4 & 3.9269 \\
\hline & Age & 4 & 3 & 3 & 4 & 4 & 7 & 3 & 3.8303 \\
\hline & Market Value & 6 & 4 & 4 & 3 & 5 & 3 & 3 & 3.8683 \\
\hline & Graduate & 5 & 2 & 2 & 3 & 5 & 4 & 3 & 3.2214 \\
\hline & Club Skills & 5 & 3 & 3 & 5 & 4 & 4 & 4 & 3.9269 \\
\hline
\end{tabular}

In the first stage of the proposed model, 22 different criteria were determined; and according to the members of the board, 5 of them were eliminated since they didn't have sufficient significance. They evaluated these eliminated criteria as they cannot affect the player performance directly. Next, the decision alternatives were determined together with the experts. The decision alternatives are presented in the following table.

Table 3

The selection criteria for goalkeeper selection and relative importance scores.

\begin{tabular}{llllll}
\hline Code & Goalkeeper & Team & Code & Goalkeeper & Team \\
\hline $\boldsymbol{A 1}$ & Ben Foster & Watford & $\boldsymbol{A 1 1}$ & Nick Pope & Burnley \\
$\boldsymbol{A 2}$ & Jordan Pickford & Everton & $\boldsymbol{A 1 2}$ & Rui Patricio & Wolverhampton \\
$\boldsymbol{A 3}$ & Kasper Schmeichel & Leicester & $\boldsymbol{A 1 3}$ & Tim Krul & Norwich \\
$\boldsymbol{A 4}$ & Martin Dubravka & Newcastle United & $\boldsymbol{A 1 4}$ & Vicente Guaita & Crystal Palace \\
$\boldsymbol{A 5}$ & Mat Ryan & Brighton & $\boldsymbol{A 1 5}$ & Ederson & Manchester City \\
$\boldsymbol{A 6}$ & Aaron Ramsdale & Bournemouth & $\boldsymbol{A 1 6}$ & Tom Heaton & Aston Villa \\
$\boldsymbol{A 7}$ & Bernd Leno & Arsenal & $\boldsymbol{A 1 7}$ & Alisson & Liverpool \\
$\boldsymbol{A 8}$ & David de Gea & Manchester United & $\boldsymbol{A 1 8}$ & Paulo Gazzaniga & Tottenham \\
$\boldsymbol{A 9}$ & Dean Henderson & Sheffield United & $\boldsymbol{A 1 9}$ & Alex McCarthy & Southampton \\
$\boldsymbol{A 1 0}$ & Kepa Arrizabalaga & Chelsea & & & \\
\end{tabular}


Then, implementation of the proposed integrated MCDM approach is performed to compute the weights of the criteria and determining the preference ratings of the decision alternatives.

4.1. Determining the new values of matrix elements: Since there is the value of zero in the indexes, it is required to compute new positive values of the elements by applying the negative transformation; and the $\mathrm{Z}$ scores are calculated by following the basic algorithm of the technique. Initially, the initial decision matrix is contructed by using raw data collected from F.A Premier League statistical database. The set of raw data is presented in Table 4.

Table 4

Original Data for Goalkeepers in the Premier League.

\begin{tabular}{|c|c|c|c|c|c|c|c|c|c|c|c|c|c|c|c|c|c|}
\hline & C1 & $\mathrm{C2}$ & C3 & $\mathrm{C4}$ & C5 & C6 & C7 & C8 & C9 & $\mathbf{C 1 0}$ & C11 & $\mathrm{C12}$ & $\mathrm{C13}$ & $\mathrm{C14}$ & C15 & $\mathrm{C16}$ & C17 \\
\hline A1 & 0.00 & 0.00 & 0.00 & 0.10 & 0.00 & 0.00 & 0.00 & 0.60 & 3.20 & 0.00 & 0.30 & 0.00 & 8.00 & 2.80 & 1.44 & 8.00 & 0.96 \\
\hline A2 & 0.00 & 0.10 & 0.10 & 0.00 & 0.00 & 0.00 & 0.00 & 0.70 & 2.50 & 0.00 & 0.30 & 0.00 & 8.50 & 9.50 & 1.40 & 6.00 & 1.38 \\
\hline A3 & 0.00 & 0.00 & 0.00 & 0.20 & 0.00 & 0.00 & 0.00 & 0.40 & 2.60 & 0.00 & 0.30 & 0.10 & 6.20 & 14.60 & 1.04 & 8.00 & 1.96 \\
\hline A4 & 0.00 & 0.00 & 0.00 & 0.00 & 0.00 & 0.00 & 0.00 & 1.00 & 4.10 & 0.10 & 0.20 & 0.00 & 8.50 & 4.40 & 1.44 & 7.00 & 1.24 \\
\hline A5 & 0.00 & 0.10 & 0.00 & 0.10 & 0.00 & 0.00 & 0.00 & 0.50 & 3.40 & 0.00 & 0.30 & 0.00 & 6.00 & 20.40 & 1.48 & 5.00 & 1.04 \\
\hline A6 & 0.10 & 0.00 & 0.00 & 0.10 & 0.00 & 0.00 & 0.00 & 1.30 & 3.50 & 0.00 & 0.30 & 0.20 & 5.50 & 9.20 & 1.46 & 4.00 & 1.09 \\
\hline A7 & 0.00 & 0.10 & 0.00 & 0.10 & 0.00 & 0.10 & 0.00 & 0.90 & 3.70 & 0.00 & 0.30 & 0.10 & 2.40 & 16.70 & 1.42 & 4.00 & 1.25 \\
\hline A8 & 0.00 & 0.00 & 0.00 & 0.20 & 0.00 & 0.10 & 0.00 & 0.50 & 2.50 & 0.00 & 0.30 & 0.00 & 2.50 & 12.50 & 1.21 & 4.00 & 1.42 \\
\hline A9 & 0.00 & 0.00 & 0.00 & 0.10 & 0.00 & 0.10 & 0.00 & 0.70 & 2.60 & 0.10 & 0.50 & 0.00 & 6.80 & 2.00 & 0.83 & 8.00 & 1.52 \\
\hline A10 & 0.00 & 0.00 & 0.00 & 0.20 & 0.00 & 0.00 & 0.00 & 0.40 & 1.70 & 0.00 & 0.20 & 0.00 & 3.80 & 18.40 & 1.33 & 5.00 & 1.67 \\
\hline A11 & 0.00 & 0.00 & 0.10 & 0.20 & 0.00 & 0.00 & 0.00 & 0.50 & 3.10 & 0.00 & 0.50 & 0.00 & 7.80 & 2.30 & 1.58 & 8.00 & 1.25 \\
\hline A12 & 0.00 & 0.00 & 0.00 & 0.20 & 0.00 & 0.00 & 0.00 & 0.30 & 2.50 & 0.00 & 0.30 & 0.00 & 6.90 & 5.20 & 1.33 & 4.00 & 1.36 \\
\hline A13 & 0.00 & 0.00 & 0.00 & 0.20 & 0.00 & 0.20 & 0.00 & 1.10 & 3.50 & 0.00 & 0.60 & 0.00 & 6.40 & 14.60 & 1.74 & 4.00 & 0.78 \\
\hline A14 & 0.00 & 0.00 & 0.00 & 0.20 & 0.00 & 0.00 & 0.00 & 1.30 & 3.00 & 0.00 & 0.60 & 0.00 & 6.80 & 6.50 & 1.04 & 6.00 & 1.32 \\
\hline A15 & 0.00 & 0.10 & 0.00 & 0.10 & 0.10 & 0.10 & 0.00 & 0.50 & 2.00 & 0.00 & 0.40 & 0.00 & 3.40 & 15.70 & 0.95 & 8.00 & 2.14 \\
\hline A16 & 0.20 & 0.10 & 0.00 & 0.10 & 0.10 & 0.00 & 0.00 & 0.60 & 3.40 & 0.10 & 0.40 & 0.00 & 6.00 & 7.80 & 1.75 & 4.00 & 1.05 \\
\hline A17 & 0.00 & 0.10 & 0.00 & 0.10 & 0.10 & 0.00 & 0.10 & 0.70 & 2.40 & 0.00 & 0.20 & 0.00 & 4.40 & 19.90 & 0.65 & 6.00 & 2.88 \\
\hline A18 & 0.00 & 0.00 & 0.10 & 0.10 & 0.10 & 0.10 & 0.00 & 0.40 & 3.30 & 0.00 & 0.30 & 0.00 & 4.30 & 10.10 & 1.44 & 2.00 & 1.18 \\
\hline A19 & 0.00 & 0.00 & 0.00 & 0.10 & 0.10 & 0.00 & 0.00 & 0.80 & 2.90 & 0.00 & 0.50 & 0.10 & 6.30 & 4.00 & 1.40 & 3.00 & 1.53 \\
\hline
\end{tabular}

As this paper focuses on the goalkeepers' performance, other players who play in different positions have not been considered, and have not been included in the scope of this study. At the beginning of the research, a board of experts was constructed in order to obtain applicable, extensive, and realistic results in the research; and selection criteria and decision alternatives were determined together with this board. In the initial stage of the assessment process, statistical data collected from the official database of the English Premier League Association and stats published by clubs were collected. Afterwards, a numerical analysis was performed using the proposed hybrid MCDM model. The values in Table 2 represent original data collected from official statistics; and if we look carefully at this table, it can be seen that numerical values of some index are zero. Therefore, negative value transformation was performed; and standard scores were computed by using equation 1; and the standard score matrix was constructed. In the second step of this technique, the absolute value of the minimum value in the standardized matrix was calculated as 2.34. The value of 0.10 was added; and the score of A was computed. With the help of equation 2 , the values of elements of the decision matrix were computed; and the decision matrix was constructed, as can be seen in Table 3 .

Table 5

The Decision Matrix.

\begin{tabular}{|c|c|c|c|c|c|c|c|c|c|c|c|c|c|c|c|c|c|}
\hline & $\mathrm{C1}$ & $\mathrm{C2}$ & C3 & $\mathrm{C} 4$ & C5 & C6 & C7 & C8 & C9 & $\mathrm{C} 10$ & C11 & $\mathrm{C} 12$ & C13 & C14 & C15 & $\mathrm{C} 16$ & C17 \\
\hline A1 & 2.12 & 1.76 & 2.01 & 2.03 & 1.85 & 1.81 & 2.21 & 2.12 & 2.88 & 2.01 & 1.97 & 1.96 & 3.63 & 1.19 & 2.89 & 3.79 & 1.46 \\
\hline A2 & 2.12 & 3.92 & 4.75 & 0.46 & 1.85 & 1.81 & 2.21 & 2.46 & 1.70 & 2.01 & 1.97 & 1.96 & 3.91 & 2.30 & 2.75 & 2.72 & 2.35 \\
\hline A3 & 2.12 & 1.76 & 2.01 & 3.60 & 1.85 & 1.81 & 2.21 & 1.44 & 1.87 & 2.01 & 1.97 & 3.79 & 2.65 & 3.15 & 1.48 & 3.79 & 3.59 \\
\hline A4 & 2.12 & 1.76 & 2.01 & 0.46 & 1.85 & 1.81 & 2.21 & 3.49 & 4.39 & 4.75 & 1.16 & 1.96 & 3.91 & 1.45 & 2.89 & 3.26 & 2.06 \\
\hline A5 & 2.12 & 3.92 & 2.01 & 2.03 & 1.85 & 1.81 & 2.21 & 1.78 & 3.21 & 2.01 & 1.97 & 1.96 & 2.54 & 4.12 & 3.03 & 2.19 & 1.63 \\
\hline A6 & 4.17 & 1.76 & 2.01 & 2.03 & 1.85 & 1.81 & 2.21 & 4.51 & 3.38 & 2.01 & 1.97 & 5.62 & 2.27 & 2.25 & 2.96 & 1.66 & 1.74 \\
\hline A7 & 2.12 & 3.92 & 2.01 & 2.03 & 1.85 & 3.53 & 2.21 & 3.15 & 3.72 & 2.01 & 1.97 & 3.79 & 0.58 & 3.50 & 2.81 & 1.66 & 2.08 \\
\hline A8 & 2.12 & 1.76 & 2.01 & 3.60 & 1.85 & 3.53 & 2.21 & 1.78 & 1.70 & 2.01 & 1.97 & 1.96 & 0.64 & 2.80 & 2.08 & 1.66 & 2.44 \\
\hline A9 & 2.12 & 1.76 & 2.01 & 2.03 & 1.85 & 3.53 & 2.21 & 2.46 & 1.87 & 4.75 & 3.60 & 1.96 & 2.98 & 1.05 & 0.76 & 3.79 & 2.65 \\
\hline A10 & 2.12 & 1.76 & 2.01 & 3.60 & 1.85 & 1.81 & 2.21 & 1.44 & 0.36 & 2.01 & 1.16 & 1.96 & 1.35 & 3.79 & 2.52 & 2.19 & 2.97 \\
\hline A11 & 2.12 & 1.76 & 4.75 & 3.60 & 1.85 & 1.81 & 2.21 & 1.78 & 2.71 & 2.01 & 3.60 & 1.96 & 3.53 & 1.10 & 3.40 & 3.79 & 2.08 \\
\hline A12 & 2.12 & 1.76 & 2.01 & 3.60 & 1.85 & 1.81 & 2.21 & 1.10 & 1.70 & 2.01 & 1.97 & 1.96 & 3.03 & 1.59 & 2.52 & 1.66 & 2.31 \\
\hline A13 & 2.12 & 1.76 & 2.01 & 3.60 & 1.85 & 5.25 & 2.21 & 3.83 & 3.38 & 2.01 & 4.42 & 1.96 & 2.76 & 3.15 & 3.95 & 1.66 & 1.08 \\
\hline A14 & 2.12 & 1.76 & 2.01 & 3.60 & 1.85 & 1.81 & 2.21 & 4.51 & 2.54 & 2.01 & 4.42 & 1.96 & 2.98 & 1.80 & 1.50 & 2.72 & 2.23 \\
\hline A15 & 2.12 & 3.92 & 2.01 & 2.03 & 4.12 & 3.53 & 2.21 & 1.78 & 0.86 & 2.01 & 2.79 & 1.96 & 1.13 & 3.34 & 1.18 & 3.79 & 3.97 \\
\hline A16 & 6.22 & 3.92 & 2.01 & 2.03 & 4.12 & 1.81 & 2.21 & 2.12 & 3.21 & 4.75 & 2.79 & 1.96 & 2.54 & 2.02 & 3.99 & 1.66 & 1.65 \\
\hline A17 & 2.12 & 3.92 & 2.01 & 2.03 & 4.12 & 1.81 & 6.69 & 2.46 & 1.53 & 2.01 & 1.16 & 1.96 & 1.67 & 4.04 & 0.10 & 2.72 & 5.54 \\
\hline A18 & 2.12 & 1.76 & 4.75 & 2.03 & 4.12 & 3.53 & 2.21 & 1.44 & 3.05 & 2.01 & 1.97 & 1.96 & 1.62 & 2.40 & 2.88 & 0.59 & 1.93 \\
\hline A19 & 2.12 & 1.76 & 2.01 & 2.03 & 4.12 & 1.81 & 2.21 & 2.80 & 2.37 & 2.01 & 3.60 & 3.79 & 2.71 & 1.39 & 2.75 & 1.12 & 2.67 \\
\hline
\end{tabular}

4.2. Calculation of the Weights of the Criteria: In this phase, both the CRITIC technique and the PSI method were applied to calculate the criteria weights. 
a) Implementing the CRITIC Technique: We applied the CRITIC technique to calculate the criteria weights by following the basic algorithm of the weighting technique as follows. In the first step, the initial decision matrix constructed in the previous step is used similarly. Next, by using equation the initial decision matrix elements were normalized as follows.

Table 6

The Normalized Matrix

\begin{tabular}{|c|c|c|c|c|c|c|c|c|c|c|c|c|c|c|c|c|c|}
\hline & Max & $\operatorname{Max}$ & $\operatorname{Max}$ & $\operatorname{Max}$ & Min & Min & Min & $\operatorname{Max}$ & $\operatorname{Max}$ & Min & Max & Min & Max & Max & Max & Max & Max \\
\hline & $C 1$ & $C 2$ & C3 & $C 4$ & C5 & C6 & C7 & $C 8$ & $C^{9}$ & C10 & C11 & C12 & C13 & C14 & C15 & C16 & $\mathrm{Cl1}$ \\
\hline A1 & 0.34 & 0.45 & 0.42 & 0.56 & 1.000 & 1.000 & 1.000 & 0.47 & 0.655 & 1.000 & 0.447 & 1.00 & 0.930 & 0.288 & 0.726 & 1.000 & 0.264 \\
\hline A2 & 0.34 & 1.00 & 1.00 & 0.13 & 1.000 & 1.000 & 1.000 & 0.55 & 0.387 & 1.000 & 0.447 & 1.00 & 1.000 & 0.559 & 0.691 & 0.719 & 0.425 \\
\hline A3 & 0.34 & 0.45 & 0.42 & 1.00 & 1.000 & 1.000 & 1.000 & 0.32 & 0.426 & 1.000 & 0.447 & 0.52 & 0.679 & 0.765 & 0.372 & 1.000 & 0.647 \\
\hline A4 & 0.34 & 0.45 & 0.42 & 0.13 & 1.000 & 1.000 & 1.000 & 0.77 & 1.000 & 0.423 & 0.262 & 1.00 & 1.000 & 0.353 & 0.726 & 0.859 & 0.371 \\
\hline A5 & 0.34 & 1.00 & 0.42 & 0.56 & 1.000 & 1.000 & 1.000 & 0.39 & 0.732 & 1.000 & 0.447 & 1.00 & 0.651 & 1.000 & 0.761 & 0.578 & 0.294 \\
\hline A6 & 0.67 & 0.45 & 0.42 & 0.56 & 1.000 & 1.000 & 1.000 & 1.00 & 0.770 & 1.000 & 0.447 & 0.35 & 0.582 & 0.547 & 0.742 & 0.437 & 0.313 \\
\hline A7 & 0.34 & 1.00 & 0.42 & 0.56 & 1.000 & 0.513 & 1.000 & 0.70 & 0.847 & 1.000 & 0.447 & 0.52 & 0.149 & 0.850 & 0.705 & 0.437 & 0.375 \\
\hline A8 & 0.34 & 0.45 & 0.42 & 1.00 & 1.000 & 0.513 & 1.000 & 0.39 & 0.387 & 1.000 & 0.447 & 1.00 & 0.163 & 0.680 & 0.521 & 0.437 & 0.440 \\
\hline A9 & 0.34 & 0.45 & 0.42 & 0.56 & 1.000 & 0.513 & 1.000 & 0.55 & 0.426 & 0.423 & 0.816 & 1.00 & 0.763 & 0.256 & 0.190 & 1.000 & 0.478 \\
\hline A10 & 0.34 & 0.45 & 0.42 & 1.00 & 1.000 & 1.000 & 1.000 & 0.32 & 0.081 & 1.000 & 0.262 & 1.00 & 0.344 & 0.919 & 0.632 & 0.578 & 0.536 \\
\hline A11 & 0.34 & 0.45 & 1.00 & 1.00 & 1.000 & 1.000 & 1.000 & 0.39 & 0.617 & 1.000 & 0.816 & 1.00 & 0.902 & 0.268 & 0.853 & 1.000 & 0.375 \\
\hline A12 & 0.34 & 0.45 & 0.42 & 1.00 & 1.000 & 1.000 & 1.000 & 0.24 & 0.387 & 1.000 & 0.447 & 1.00 & 0.777 & 0.385 & 0.632 & 0.437 & 0.417 \\
\hline A13 & 0.34 & 0.45 & 0.42 & 1.00 & 1.000 & 0.345 & 1.000 & 0.85 & 0.770 & 1.000 & 1.000 & 1.00 & 0.707 & 0.765 & 0.990 & 0.437 & 0.195 \\
\hline A14 & 0.34 & 0.45 & 0.42 & 1.00 & 1.000 & 1.000 & 1.000 & 1.00 & 0.579 & 1.000 & 1.000 & 1.00 & 0.763 & 0.438 & 0.375 & 0.719 & 0.402 \\
\hline A15 & 0.34 & 1.00 & 0.42 & 0.56 & 0.448 & 0.513 & 1.000 & 0.39 & 0.196 & 1.000 & 0.631 & 1.00 & 0.289 & 0.810 & 0.295 & 1.000 & 0.716 \\
\hline A16 & 1.00 & 1.00 & 0.42 & 0.56 & 0.448 & 1.000 & 1.000 & 0.47 & 0.732 & 0.423 & 0.631 & 1.00 & 0.651 & 0.490 & 1.000 & 0.437 & 0.298 \\
\hline A17 & 0.34 & 1.00 & 0.42 & 0.56 & 0.448 & 1.000 & 0.330 & 0.55 & 0.349 & 1.000 & 0.262 & 1.00 & 0.428 & 0.980 & 0.025 & 0.719 & 1.000 \\
\hline A18 & 0.34 & 0.45 & 1.00 & 0.56 & 0.448 & 0.513 & 1.000 & 0.32 & 0.694 & 1.000 & 0.447 & 1.00 & 0.414 & 0.583 & 0.724 & 0.156 & 0.348 \\
\hline A19 & 0.34 & 0.45 & 0.42 & 0.56 & 0.448 & 1.000 & 1.000 & 0.62 & 0.541 & 1.000 & 0.816 & 0.52 & 0.693 & 0.336 & 0.691 & 0.296 & 0.482 \\
\hline Avr. & 0.393 & 0.624 & 0.514 & 0.678 & 0.855 & 0.837 & 0.965 & 0.542 & 0.557 & 0.909 & 0.553 & 0.890 & 0.626 & 0.593 & 0.613 & 0.645 & 0.441 \\
\hline$\sigma$ & 0.165 & 0.262 & 0.216 & 0.285 & 0.250 & 0.249 & 0.154 & 0.228 & 0.234 & 0.216 & 0.233 & 0.222 & 0.263 & 0.249 & 0.258 & 0.271 & 0.185 \\
\hline
\end{tabular}

In the rest of the implementation steps of the technique, the correlation coefficients of the indexes were calculated by using equation 6. After the conflict of the index $C_{i}$ was computed as follows.

Table 7

The Correlation Matrix

\begin{tabular}{|c|c|c|c|c|c|c|c|c|c|c|c|c|c|c|c|c|c|}
\hline & C1 & C2 & C3 & C4 & C5 & C6 & C7 & C8 & C9 & C10 & C11 & $\mathrm{C} 12$ & C13 & C14 & $\mathrm{C15}$ & C16 & C17 \\
\hline C1 & 1.00 & 0.24 & -0.14 & -0.13 & -0.30 & 0.22 & 0.08 & 0.15 & 0.27 & -0.45 & 0.02 & -0.16 & 0.00 & -0.11 & 0.39 & -0.25 & -0.25 \\
\hline C2 & 0.24 & 1.00 & 0.02 & -0.46 & -0.37 & 0.00 & -0.35 & -0.10 & -0.05 & -0.02 & -0.23 & 0.09 & -0.26 & 0.53 & -0.09 & 0.01 & 0.29 \\
\hline C3 & -0.14 & 0.02 & 1.00 & -0.18 & -0.07 & 0.00 & 0.10 & -0.24 & 0.02 & 0.19 & 0.03 & 0.22 & 0.25 & -0.22 & 0.25 & -0.03 & -0.14 \\
\hline C4 & -0.13 & -0.46 & -0.18 & 1.00 & 0.25 & -0.11 & 0.10 & -0.19 & -0.34 & 0.41 & 0.34 & 0.03 & -0.26 & 0.12 & -0.04 & -0.06 & 0.01 \\
\hline C5 & -0.30 & -0.37 & -0.07 & 0.25 & 1.00 & 0.08 & 0.39 & 0.19 & 0.14 & 0.07 & -0.01 & -0.04 & 0.30 & -0.11 & 0.16 & 0.28 & -0.42 \\
\hline C6 & 0.22 & 0.00 & 0.00 & -0.11 & 0.08 & 1.00 & -0.16 & -0.03 & -0.02 & 0.00 & -0.29 & -0.11 & 0.51 & -0.19 & 0.05 & 0.19 & 0.10 \\
\hline C7 & 0.08 & -0.35 & 0.10 & 0.10 & 0.39 & -0.16 & 1.00 & 0.00 & 0.21 & -0.10 & 0.30 & -0.12 & 0.18 & -0.38 & 0.55 & -0.07 & -0.73 \\
\hline C8 & 0.15 & -0.10 & -0.24 & -0.19 & 0.19 & -0.03 & 0.00 & 1.00 & 0.52 & -0.11 & 0.37 & -0.33 & 0.18 & -0.15 & 0.09 & -0.09 & -0.26 \\
\hline C9 & 0.27 & -0.05 & 0.02 & -0.34 & 0.14 & -0.02 & 0.21 & 0.52 & 1.00 & -0.31 & 0.11 & -0.22 & 0.29 & -0.25 & 0.58 & -0.22 & -0.64 \\
\hline C10 & -0.45 & -0.02 & 0.19 & 0.41 & 0.07 & 0.00 & -0.10 & -0.11 & -0.31 & 1.00 & -0.03 & -0.22 & -0.30 & 0.41 & -0.04 & -0.20 & 0.14 \\
\hline C11 & 0.02 & -0.23 & 0.03 & 0.34 & -0.01 & -0.29 & 0.30 & 0.37 & 0.11 & -0.03 & 1.00 & 0.05 & 0.24 & -0.38 & 0.12 & 0.04 & -0.30 \\
\hline C12 & -0.16 & 0.09 & 0.22 & 0.03 & -0.04 & -0.11 & -0.12 & -0.33 & -0.22 & -0.22 & 0.05 & 1.00 & 0.19 & -0.05 & -0.05 & 0.21 & -0.01 \\
\hline C13 & 0.00 & -0.26 & 0.25 & -0.26 & 0.30 & 0.51 & 0.18 & 0.18 & 0.29 & -0.30 & 0.24 & 0.19 & 1.00 & -0.65 & 0.25 & 0.39 & -0.34 \\
\hline C14 & -0.11 & 0.53 & -0.22 & 0.12 & -0.11 & -0.19 & -0.38 & -0.15 & -0.25 & 0.41 & -0.38 & -0.05 & -0.65 & 1.00 & -0.19 & -0.19 & 0.39 \\
\hline C15 & 0.39 & -0.09 & 0.25 & -0.04 & 0.16 & 0.05 & 0.55 & 0.09 & 0.58 & -0.04 & 0.12 & -0.05 & 0.25 & -0.19 & 1.00 & -0.43 & -0.83 \\
\hline C16 & -0.25 & 0.01 & -0.03 & -0.06 & 0.28 & 0.19 & -0.07 & -0.09 & -0.22 & -0.20 & 0.04 & 0.21 & 0.39 & -0.19 & -0.43 & 1.00 & 0.31 \\
\hline C17 & -0.25 & 0.29 & -0.14 & 0.01 & -0.42 & 0.10 & -0.73 & -0.26 & -0.64 & 0.14 & -0.30 & -0.01 & -0.34 & 0.39 & -0.83 & 0.31 & 1.00 \\
\hline$C_{j}$ & 2.713 & 4.391 & 3.447 & 4.711 & 3.855 & 3.918 & 2.456 & 3.643 & 3.725 & 3.582 & 3.630 & 3.671 & 3.948 & 4.351 & 3.926 & 4.363 & 3.462 \\
\hline
\end{tabular}

Finally, the weights of the criteria were determined with the help of equation 8 . The values of $r_{i j}, C_{i}$, and $w_{j}$ are represented in Table 7.

Table 8

The criteria weights obtained by using the CRITIC technique

\begin{tabular}{cccc}
\hline Criteria & Weights & Criteria & Weights \\
\hline C1 & 0.0425 & C10 & 0.0562 \\
C2 & 0.0688 & C11 & 0.0569 \\
C3 & 0.0540 & C12 & 0.0575 \\
C4 & 0.0738 & C13 & 0.0619 \\
C5 & 0.0604 & C14 & 0.0682 \\
C6 & 0.0614 & $\mathrm{C} 15$ & 0.0615 \\
C7 & 0.0385 & $\mathrm{C} 16$ & 0.0684 \\
C8 & 0.0571 & C17 & 0.0543 \\
C9 & 0.0584 & & \\
\hline
\end{tabular}

b) Implementing the PSI Technique: In the first two implementation steps of the PSI technique, the elements of the decision matrix (Table 3) were normalized as in the normalization operation performed by applying the CRITIC technique. As the normalized matrix is presented in Table 4, it has not been given in this section again. After the normalized matrix is generated, the preference variation value $\left(\phi_{j}\right)$ for each attribute is computed by using Eq. (12). Then, by applying equation 
13 , the deviation of preference value for each attribute $\left(\Omega_{j}\right)$ is computed; and the weight values of the selection criteria ( $w_{j}$ ) are determined with the help of equation 14 . The obtained values are given in Table 8.

Table 9

The $\phi_{j}, \Omega_{j}$, and criteria weights $w_{j}$ for each attribute

\begin{tabular}{|c|c|c|c|c|c|c|c|}
\hline Criteria & $\phi_{j}$ & $\Omega_{j}$ & $w_{j}$ & Criteria & $\phi_{j}$ & $\Omega_{j}$ & $w_{j}$ \\
\hline $\mathrm{C1}$ & 0.4914 & 0.5086 & 0.1332 & C10 & 0.8409 & 0.1591 & 0.0417 \\
\hline $\mathrm{C} 2$ & 1.2389 & 0.2389 & 0.0626 & C11 & 0.9742 & 0.0258 & 0.0068 \\
\hline C3 & 0.8409 & 0.1591 & 0.0417 & C12 & 0.8895 & 0.1105 & 0.0289 \\
\hline $\mathrm{C4}$ & 1.4638 & 0.4638 & 0.1214 & $\mathrm{C} 13$ & 1.2448 & 0.2448 & 0.0641 \\
\hline C5 & 1.1207 & 0.1207 & 0.0316 & C14 & 1.1195 & 0.1195 & 0.0313 \\
\hline C6 & 1.1133 & 0.1133 & 0.0297 & C15 & 1.1961 & 0.1961 & 0.0513 \\
\hline C7 & 0.4249 & 0.5751 & 0.1506 & C16 & 1.3213 & 0.3213 & 0.0841 \\
\hline C8 & 0.9337 & 0.0663 & 0.0173 & C17 & 0.6180 & 0.3820 & 0.1000 \\
\hline C9 & 0.9858 & 0.0142 & 0.0037 & & & & \\
\hline
\end{tabular}

c) Combining the weights of the criteria: After the criteria weights were calculated by applying both weighing techniques, the computed weights of the criteria were combined with the help of weight aggregation operator. For this purpose, equation 15 is used. The obtained results are given in Table 10.

Table 10

The final aggregated criteria weights $w_{j}$ for each attributes

\begin{tabular}{|c|c|c|c|c|c|c|c|c|c|}
\hline Criteria & $S_{j}$ & $k_{j}$ & $s_{j} x k_{j}$ & $w_{j}$ & Criteria & $S_{j}$ & $k_{j}$ & $s_{j} x k_{j}$ & $w_{j}$ \\
\hline C1 & 0.0425 & 0.1332 & 0.0057 & 0.0998 & C10 & 0.0562 & 0.0417 & 0.0023 & 0.0412 \\
\hline $\mathrm{C} 2$ & 0.0688 & 0.0626 & 0.0043 & 0.0759 & C11 & 0.0569 & 0.0068 & 0.0004 & 0.0068 \\
\hline C3 & 0.0540 & 0.0417 & 0.0023 & 0.0397 & $\mathrm{C} 12$ & 0.0575 & 0.0289 & 0.0017 & 0.0293 \\
\hline $\mathrm{C} 4$ & 0.0738 & 0.1214 & 0.0090 & 0.1580 & C13 & 0.0619 & 0.0641 & 0.0040 & 0.0699 \\
\hline C5 & 0.0604 & 0.0316 & 0.0019 & 0.0337 & C14 & 0.0682 & 0.0313 & 0.0021 & 0.0376 \\
\hline C6 & 0.0614 & 0.0297 & 0.0018 & 0.0321 & C15 & 0.0615 & 0.0513 & 0.0032 & 0.0557 \\
\hline C7 & 0.0385 & 0.1506 & 0.0058 & 0.1021 & C16 & 0.0684 & 0.0841 & 0.0058 & 0.1014 \\
\hline C8 & 0.0571 & 0.0173 & 0.0010 & 0.0175 & C17 & 0.0543 & 0.1000 & 0.0054 & 0.0956 \\
\hline C9 & 0.0584 & 0.0037 & 0.0002 & 0.0038 & & & & & \\
\hline
\end{tabular}

d) Implementation of the WASPAS Technique: Because implementation of the first two steps is the same as the first two steps of both weighting techniques, these steps are not given in this section again. Therefore, implementation and obtained results are completely the same. In the rest of the steps in the WASPAS method, the WSM and the WSP values for each alternative with respect to the criteria were calculated by using equations 17 and 18 , respectively. Next, the aggregated measure for each alternative is computed with the help of equation 19; and the decision alternatives were ranked considering their aggregated measures. The obtained values are presented in Table 11.

Table 11

The WSM, WSP, the aggregated performance scores of the options and ranking

\begin{tabular}{|c|c|c|c|c|c|c|c|c|c|}
\hline Options & $W S M\left(p_{i}{ }^{l}\right)$ & $W S P\left(p_{i}^{2}\right)$ & Score $\left(p_{i}\right)$ & Ranking & Options & $W S M\left(p_{i}{ }^{l}\right)$ & $W S P\left(p_{i}^{2}\right)$ & Score $\left(p_{i}\right)$ & Ranking \\
\hline A1 & 0.67 & 0.60 & 0.63 & 10 & A11 & 0.78 & 0.71 & 0.74 & 1 \\
\hline A2 & 0.66 & 0.54 & 0.60 & 12 & A12 & 0.68 & 0.62 & 0.65 & 7 \\
\hline A3 & 0.74 & 0.68 & 0.71 & 2 & A13 & 0.68 & 0.60 & 0.64 & 8 \\
\hline A4 & 0.58 & 0.48 & 0.53 & 18 & A14 & 0.71 & 0.65 & 0.68 & 3 \\
\hline A5 & 0.68 & 0.62 & 0.65 & 6 & A15 & 0.67 & 0.61 & 0.64 & 9 \\
\hline A6 & 0.63 & 0.59 & 0.61 & 11 & A16 & 0.69 & 0.63 & 0.66 & 5 \\
\hline A7 & 0.60 & 0.54 & 0.57 & 15 & A17 & 0.62 & 0.50 & 0.56 & 16 \\
\hline A8 & 0.63 & 0.56 & 0.59 & 13 & A18 & 0.55 & 0.49 & 0.52 & 19 \\
\hline A9 & 0.61 & 0.55 & 0.58 & 14 & A19 & 0.57 & 0.53 & 0.55 & 17 \\
\hline A10 & 0.69 & 0.63 & 0.66 & 4 & & & & & \\
\hline
\end{tabular}

\section{Validation Test}

In order to test the validation of the proposed hybrid technique, a comprehensive sensitivity analysis consisting of three phases was performed. First, we examined impacts of changing the weights on the ranking performances of the alternatives. For this purpose, 170 different scenarios were formed. When the results obtained in the first phase of the sensitivity analysis are evaluated, Nick Pope determined the best alternative has also remained the best option for 168 scenarios (98.8\%). While Kasper Schmeichel has remained the second-best alternative 161 times, the ranking position of Vicente Guaita has not changed in 157 scenarios. For best players who are in the first three ranks, the average similarity between the ranking results obtained by using the proposed hybrid approach and the ranking results calculated in the formed scenarios has been determined as $95.3 \%$. Impacts of changing criteria weights on the ranking performances of the decision alternatives are presented in Fig. 2. 


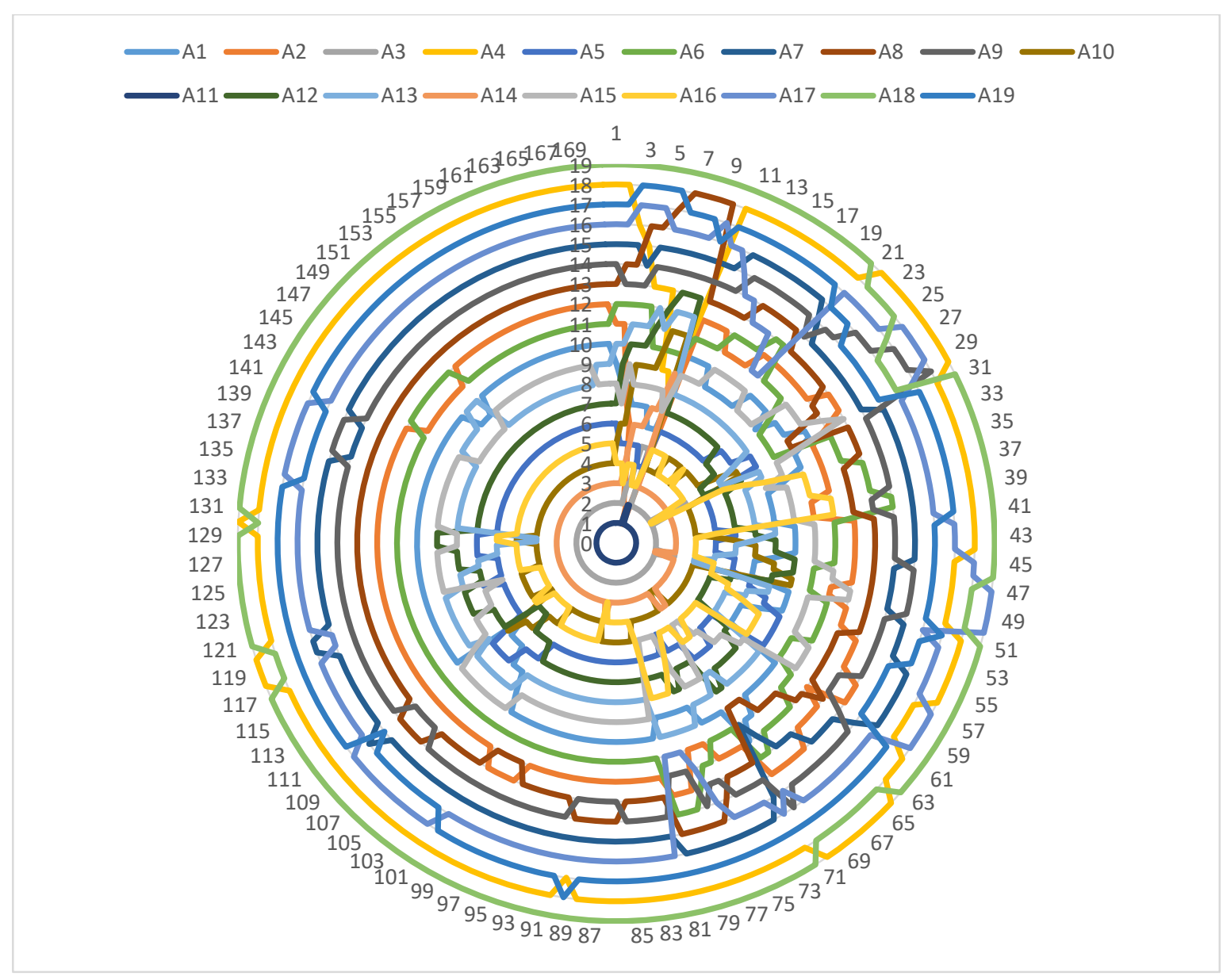

Fig. 2. Impacts of modifications of criteria weights on the ranking results for 101 scenarios

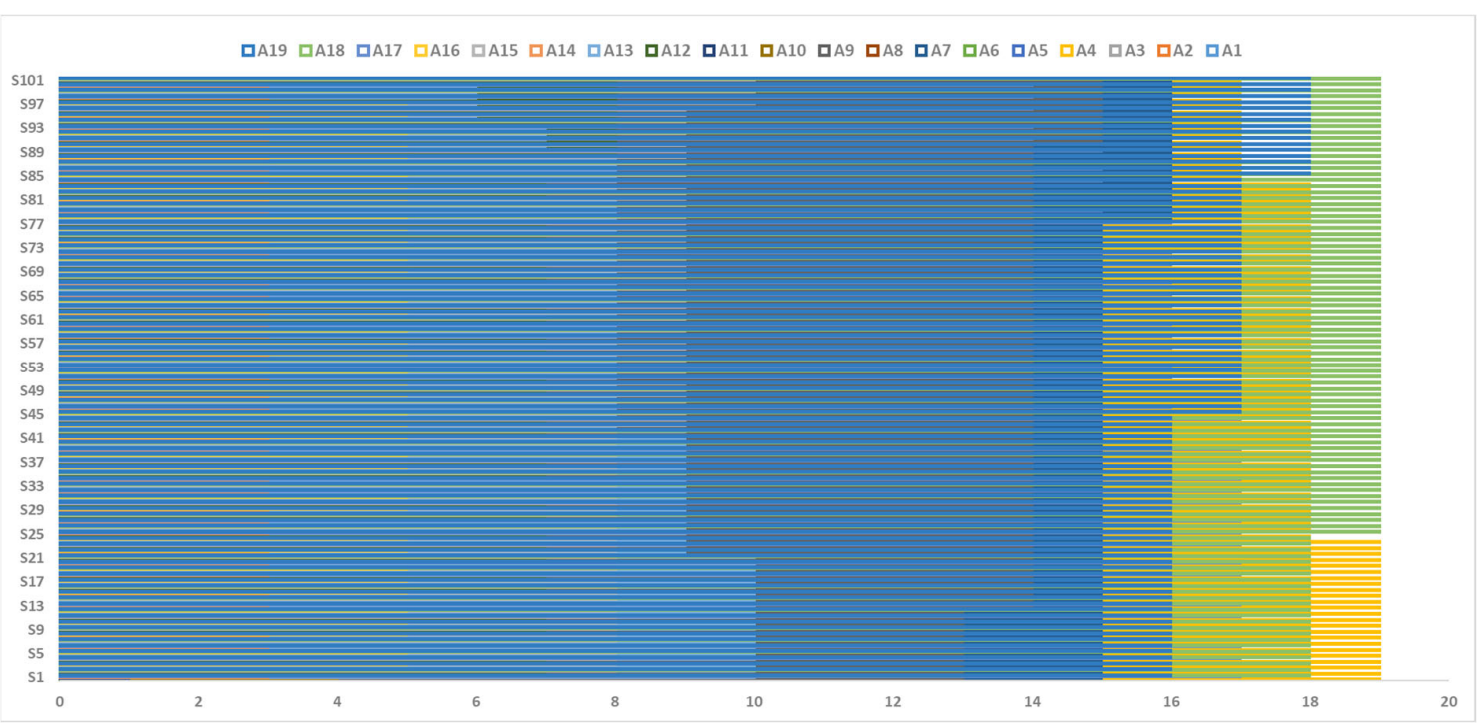

Fig. 3. Impacts of modifications of $\alpha$ parameter on the ranking results for 101 scenarios

Secondly, impacts of modification of the $\alpha$ paramaters between 0 and $1[0,1]$ on the ranking results was examined by forming 101 different scenarios; and the value of 0.01 was added into the value of parameter in each scenario. The obtained results for all scenarios are given in Figure 3. According to the results by modifying the $\alpha$ parameter, Nick Pope (A11) determined the best option by applying the proposed model. He has also remained the best alternative for all scenarios. In addition, slight changes have been observed, which cannot change, in the ranking performances of some alternatives. The obtained results are given in Fig. 3. In the third stage of the validation test, the ranking results obtained by applying the 
suggested model was compared to the ranking results of different MCDM techniques implemented in the current paper to verify the results of the proposed MCDM model. For this purpose, some MCDM techniques such as MABAC (Pamučar and Ćirović, 2015) MARCOS (Stević et.al, 2020), EDAS (Ghorabaee et al., 2015) and MAUT (Zietsman et al., 2006) were applied; and the ranking results obtained by implementing these techniques are presented in Fig. 4.

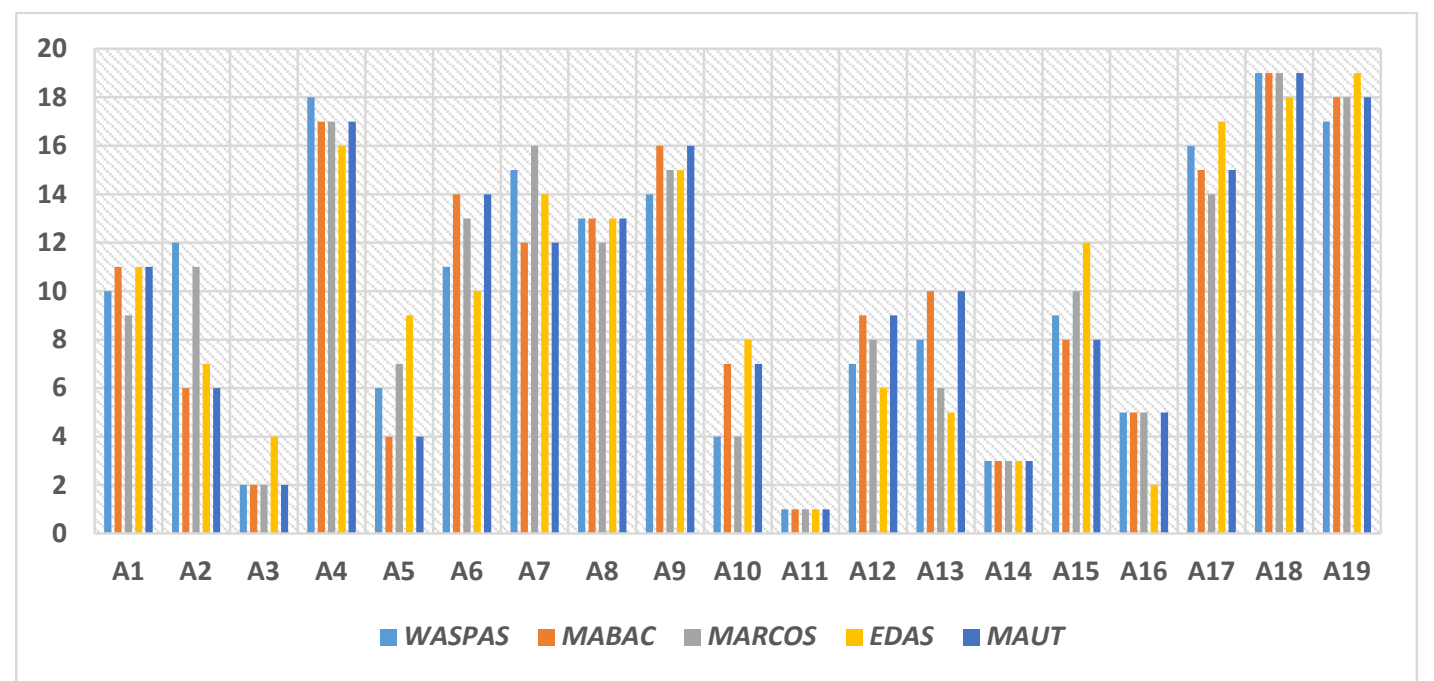

Fig. 4. Comparison between the ranking performances obtained by different techniques

Nick Pope determined the best alternative has also remained the best option for the results of the other applied MCDM techniques. In addition to that, the ranking position of Vicente Guaita (A14) who is in the 3rd rank did not change for all applied MCDM techniques either; and minor changes have been observed in the ranking performances of the decision alternatives. At the same time, when the correlations between the ranking results of the proposed model and other implemented MCDM techniques are very high, 0.937 on average. While the highest correlation is between the suggested model and the MARCOS technique ( $\mathrm{r}=0.981)$, the lowest correlation is between the model and the EDAS method (0.916).

\section{Results and Discussion}

The rankings derived from performance scores of goalkeepers calculated with the help of the proposed model are presented in Table 4 for the English Premier League 2018/2019 season. Determining realistic and rational criteria about the goalkeepers' performances is a very difficult and time-consuming process. In fact, many factors and variables affecting the goalkeepers' performances are available. In this paper, a range of criteria directly affecting the goalkeepers' performances was determined with the help of the members of the board of experts. The goalkeepers' performance scores represent the match performances; and some factors such as market value, the teams' ranking value in the league, and minutes played have not been included in the scope of the research because impacts of these kinds of factors on the overall performances of the goalkeepers are relatively weak. All data were collected from the statistical database of the Association of English Premier League; and these data were analyzed using the proposed model that consists of the CRITIC and the PSI techniques used for calculating the criteria weights; and the WASPAS methods were applied to determine the preference ratings of the decision alternatives. The obtained results are also presented in Table 11. This paper discusses whether a hybrid multicriteria decision-making model can be applied for evaluating the match performances of the goalkeepers. It was expected that the proposed MCDM model gives applicable and realistic results. When the obtained results are evaluated, it can be seen that these results are very realistic and consistent. At the same time, the members of the board also verified these results. According to them, the obtained results of this research are compatible with real life.

The top goalkeeper has been determined as Nick Pope, who is a player of the Burnley football team. He had a very good performance in the 2018/2019 season when the selection criteria in this study are considered. Especially, he can be accepted as a very successful goalkeeper in terms of goals saved, pass accuracy, and clean sheets. Paulo Gazzaniga, who is the goalkeeper of Tottenham, has been determined as the player who had the worst performance. So, indeed he had a very bad performance getting behind other competitors in the previous season; and almost all his scores about selected factors were low. The differences among performance scores of the goalkeepers, excluding Nick Pope, are low because the qualities and abilities of these kinds of players who play in the English Premier League are very high.

When the ranking results for goalkeepers are evaluated, there is a meaningful correlation between these results and ranking realized by the Association of English Premier League. Both rankings are very similar; and little differences not affecting the results exist between them. This paper proved that there is no direct relationship between performance and criterion separately; and it is possible to obtain realistic results when all factors and variables are evaluated together. For instance, Nick Pope is not the best player when only the criterion of goal saved is considered even if his performance values for some 
criteria were determined as low or intermediate. This paper has many valuable contributions to the literature. First of all, the number of studies focusing on the player selection is very limited. Furthermore, most of these papers used traditional MCDM techniques such as AHP and TOPSIS. Although they have contributions to the literature, their contributions and impacts are unfortunately limited since the AHP and TOPSIS techniques have some disadvantages. For instance, the AHP technique is mostly a criticized method with respect to the requirement for consistency analysis. Therefore, the AHP technique requires additional computations for determining consistency. In addition, it has a very complicated algorithm; and it is possible to reach the results with a great number of computations. Moreover, decision makers cannot be sure about the evaluation results obtained by using the AHP technique with respect to reliability and accuracy. Also, the TOPSIS technique is very sensitive to the number of attributes and decision alternatives. Thus, it suffers from the rank reversal problem. When a decision alternative is added or removed from the set of the options, the ranking results may change dramatically. Because of these limitations, these techniques applied by the previous studies cannot be a methodological frame that can be implemented for solving decision-making problems encountered in the field of sport management. Hence, it is required to use an applicable MCDM technique, which does not have this kind of limitations, in the sports management. For this purpose, this paper suggests an applicable and useful integrated MCDM approach. It can reach accurate and reasonable results with fewer computations; and its algorithm is easy to understand and follow for practitioners. In addition, it presents a novel weight aggregation operator to obtain more realistic and reasonable weight values of criteria.

\section{Conclusions}

The obtained results have presented that the proposed integrated multi-criteria decision-making model consisting of the CRITIC and the PSI techniques and the WASPAS methods can be applied to the decision-making problems about goalkeeper selection. The obtained results are very realistic, applicable, and consistent. Moreover, because the suggested MCDM approach provides a methodological framework, this model has the potential to be used for solving decision-making problems faced in the different fields of football and other branches of sports. In addition to those, this model can be improved by adding different MCDM methods in future studies; and it can be applied to several decision-making problems in various fields in addition to the field of sports. The proposed hybrid technique can be applied to solve very complicated player selection in the field of sport management. In this respect, the proposed technique can help future work, which will be carried out on this issue as it can be applied as a methodological frame by decision-makers in charge of player selection. This paper has also some limitations. First of all, collected data on player performance are mostly technical; and collecting some individual criteria for players such as personality, honesty, and some economic criteria would be better. Unfortunately, collecting these kinds of data is very difficult since most of them are not published by reliable sources or may not exist. Because of that, there are some ambiguities, which can affect the evaluation results. Fuzzy techniques can enable us to deal with these uncertainties in future work. In future work, the selection player problem can be evaluated by applying extended MCDM techniques with the help of fuzzy set theory, interval-valued fuzzy sets, intitutistic fuzzy sets.

\section{References}

Ballı, S., \& Korukoğlu, S. (2014). Development of a fuzzy decision support framework for complex multi-attribute decision problems: A case study for the selection of skilful basketball players. Expert Systems, 31(1), 56-69.

Casals, M., \& Martinez, A. J. (2013). Modelling player performance in basketball through mixed models. International Journal of Performance Analysis in Sport, 13(1), 64-82.

Chakraborty, S., \& Zavadskas, E. K. (2014). Applications of WASPAS method in manufacturing decision making. Informatica, 25(1), 1-20.

Deng, H., Yeh, C. H., \& Willis, R. J. (2000). Inter-company comparison using modified TOPSIS with objective weights. Computers \& Operations Research, 27(10), 963-973.

Deveci, M., Canıtez, F., \& Gökaşar, I. (2018). WASPAS and TOPSIS based interval type-2 fuzzy MCDM method for a selection of a car sharing station. Sustainable Cities and Society, 41, 777-791.

Diakoulaki, D., Mavrotas, G., \& Papayannakis, L. (1995). Determining objective weights in multiple criteria problems: The critic method. Computers \& Operations Research, 22(7), 763-770.

Djordjević, D. P., Vujošević, M., \& Martić, M. (2015). Measuring efficiency of football teams by multi-stage DEA model. Technical Gazette, 22(3), 763-770.

Duch, J., Waitzman, J. S., \& Amaral, L. A. N. (2010). Quantifying the performance of individual players in a team activity. PloS one, 5(6), e10937.

Ecer F.(2020). Çok Kriterli Karar Verme Geçmişten Günümüze Kapsamlı Bir Yaklaşım. Yayın Yeri:Seçkin Yayıncılık, Basim sayıs1:1, ISBN:978-975-02-6017-9.

Fernandez-Navarro, J., Fradua, L., Zubillaga, A., Ford, P. R., \& McRobert, A. P. (2016). Attacking and defensive styles of play in soccer: analysis of Spanish and English elite teams. Journal of Sports Sciences, 34(24), 2195-2204..

Hu, Z. H., Zhou, J. X., Zhang, M. J., \& Zhao, Y. (2015). Methods for ranking college sports coaches based on data envelopment analysis and PageRank. Expert Systems, 32(6), 652-673.

Jarvandi, A., Sarkani, S., \& Mazzuchi, T. (2013). Modeling team compatibility factors using a semi-Markov decision process: a data-driven approach to player selection in soccer. Journal of Quantitative Analysis in Sports, 9(4), $347-366$.

Jian, S., \& Yin, S. (2017). Preference Selection Index Method for Machine Selection in a Flexible Manufacturing Cell. MATEC Web of Conferences 139, 00167 (2017), ICMITE 2017, DOI: 10.1051/matecconf/201713900167. 
Karabašević, D., Stanujkić, D., Urošević, S., \& Maksimović, M. (2016). An approach to personnel selection based on SWARA and WASPAS methods. Bizinfo (Blace) Journal of Economics, Management and Informatics, 7(1), 1-11.

Karsak, E. E. (2000, October). A fuzzy multiple objective programming approach for personnel selection. In Smc 2000 conference proceedings. 2000 ieee international conference on systems, man and cybernetics.'cybernetics evolving to systems, humans, organizations, and their complex interactions'(cat. no. 0 (Vol. 3, pp. 2007-2012). IEEE.

Kedar-Levy, H., \& Bar-Eli, M. (2008). The valuation of athletes as risky investments: A theoretical model. Journal of Sport Management, 22(1), 50-81.

Keshavarz Ghorabaee, M., Zavadskas, E. K., Olfat, L., \& Turskis, Z. (2015). Multi-criteria inventory classification using a new method of evaluation based on distance from average solution (EDAS). Informatica, 26(3), 435-451.

de Korvin, A., Shipley, M. F., \& Kleyle, R. (2002). Utilizing fuzzy compatibility of skill sets for team selection in multiphase projects. Journal of Engineering and Technology Management, 19(3-4), 307-319.

Lago-Ballesteros, J., \& Lago-Peñas, C. (2010). Performance in team sports: Identifying the keys to success in soccer. Journal of Human kinetics, 25, 85-91.

Maniya K., \& Bhatt, M.G. (2010). A selection of material using a novel type decision-making method: preference selection index method. Materials \& Design., 31(4), 1785-1789.

Mardani, A., Nilashi, M., Zakuan, N., Loganathan, N., Soheilirad, S., Saman, M. Z. M., \& Ibrahim, O. (2017). A systematic review and meta-Analysis of SWARA and WASPAS methods: Theory and applications with recent fuzzy developments. Applied Soft Computing, 57, 265-292.

Mirabile, M. P., \& Witte, M. D. (2015). A discrete-choice model of a college football recruit's program selection decision. Journal of Sports Economics, 18(3), 211-238.

Pamučar, D., \& Ćirović, G. (2015). The selection of transport and handling resources in logistics centers using MultiAttributive Border Approximation area Comparison (MABAC). Expert Systems with Applications, 42(6), 3016-3028.

Qader, M. A., BB, Z., Ali, S. K., Kamaluddin, M. A., \& Radzi, W. B. (2017). A methodology for football players' selection problem based on multi- measurements criteria analysis. Measurement, 111, 38-50.

Sahir, S. H. (2018). The Preference Selection Index method in determining the location of used laptop marketing. International Journal of Engineering Technology, 7(3-4).

Stević, Ž., Pamučar, D., Puška, A., \& Chatterjee, P. (2020). Sustainable supplier selection in healthcare industries using a new MCDM method: Measurement of alternatives and ranking according to COmpromise solution (MARCOS). Computers \& Industrial Engineering, 140, 106231.

Tenga, A., Holme, I., Ronglan, L. T., \& Bahr, R. (2010). Effect of playing tactics on achieving score-box possessions in a random series of team possessions from Norwegian professional soccer matches. Journal of Sports Sciences, 28(3), 245255.

Torkayesh, A. E., Pamucar, D., Ecer, F., \& Chatterjee, P. (2021). An integrated BWM-LBWA-CoCoSo framework for evaluation of healthcare sectors in Eastern Europe. Socio-Economic Planning Sciences, 101052.

Vaeyens, R., Malina, R. M., Janssens, M., Van Renterghem, B., Bourgois, J., Vrijens, J., \& Philippaerts, R. M. (2006). A multidisciplinary selection model for youth soccer: the Ghent Youth Soccer Project. British Journal of Sports Medicine, 40(11), 928-934.

Vinchurkar, S. H., \& Samtani, B. K. (2019). Performance Evaluation of The Hydropower Plants Using Various MultiCriteria Decision-Making Techniques. International Journal of Engineering and Advanced Technology, 8, 2031-2038.

Vujić, D., Stanujkić, D., Urošević, S., \& Karabašević, D. (2016). An approach to leader selection in the mining industry based on the use of weighted sum preferred levels of the performances method. Mining and Metallurgy Engineering Bor, 4, 53-62.

Wang, Y. M., \& Luo, Y. (2010). Integration of correlations with standard deviations for determining attribute weights in multiple attribute decision making. Mathematical and Computer Modelling, 51(1-2), 1-12.

Woods, C. T., Raynor, A. J., Bruce, L., McDonald, Z., \& Robertson, S. (2016). The application of a multi-dimensional assessment approach to talent identification in Australian football. Journal of Sports Sciences, 34(14), 1340-1345.

Yazdani, M., Torkayesh, A. E., \& Chatterjee, P. (2020). An integrated decision-making model for supplier evaluation in public healthcare system: the case study of a Spanish hospital. Journal of Enterprise Information Management, 33(5),

Zhang, Q., Xu, W., \& Zhang, J. (2014). Method for determining the weight of functional objectives on manufacturing system. The Scientific World Journal, 2014.

Zhang, X., Wang, C., Li, E., \& Xu, C. (2014). Assessment model of ecoenvironmental vulnerability based on improved entropy weight method. The Scientific World Journal, 2014.

Zietsman, J., Rilett, L. R., \& Kim, S.-J. (2006). Transportation corridor decision-making with multi-attribute utility theory. International Journal of Management and Decision Making, 7(2), 254-266.

Yazdani M, Torkayesh AE, Chatterjee P. An integrated decision-making model for supplier evaluation in public healthcare system: the case study of a Spanish hospital. J Enterprise Inf Manag 2020 


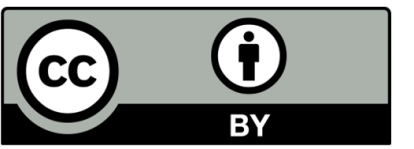

(C) 2021 by the authors; licensee Growing Science, Canada. This is an open access article distributed under the terms and conditions of the Creative Commons Attribution (CC-BY) license (http://creativecommons.org/licenses/by/4.0/). 